\title{
ATP prediction of voltage sag effect on sensitive loads
}

\author{
J. Cardona ${ }^{1}$, J. Barros ${ }^{2}$ \\ ${ }^{1}$ Department of Electrical Engineering, \\ E.T.S. Náutica, University of Cantabria \\ Dique de Gamazo, 1. 39004 Santander (Spain) \\ Phone:+34 942 201349, e-mail: cardonaj@unican.es \\ ${ }^{2}$ Department of Electronics and Computers \\ E.T.S. Náutica, University of Cantabria \\ Dique de Gamazo, 1. 39004 Santander (Spain) \\ Phone:+34 942 201355, e-mail: barrosj@unican.es
}

\begin{abstract}
The objective of this paper is to analyze the behavior of adjustable speed drives (ASD) connected to the power system under symmetrical voltage sag conditions. An ATP model has been developed to simulate the response of a VSI inverter driving a three-phase induction motor. Speed and voltage control systems are included. The response of mechanical and electrical variables is obtained.
\end{abstract}

\section{Key words}

ATP computer simulation, voltage sags, adjustable speed drives

\section{Introduction}

Voltage sags in power systems produce an important effect on the behavior of sensitive loads. Tripping of power adjustablespeed drives (ASD) is one of the greatest voltage sag problems, causing critical loads to stop with the resultant interruption of the manufacturing process several times a year. The resulting loss of time and production, or damaged equipment may cause significant economical losses.

Voltage sags are due to short duration increases of current originated in remote locations of the power system. These increases in the current are mainly caused by faults, overloads, starting of large motors and transformer energizing. Voltage sags in the terminals of a load affect the equipment's normal operation. The equipment may fail due to several causes, such as insufficient voltage for regulators, undervoltage circuit trips, unbalanced relay trips, reset circuits may incorrectly trip at the end of the voltage sag etc.

Some configurations to prevent production interruptions have been reported . One of these approaches consists in a transfer between two independent power sources[1]. This implies a fast switching transfer (less than two cycles) with a synchronized control scheme. Also the use of the motor inertia with ASD is limited to short duration sags, and there is the tripping action of internal drive [1]. An alternative is the use of uninterrumpible power supplies (UPS), of the ASD's supply side, however the cost of such a system for the critical drives in a continuous process would be unaceptable [2].
Several voltage-compensating techniques have been published: Some are based on ASD with energy storage devices [3],[4],[5]. Other references use voltage sag compensators based on ac-ac converter along with autotransformer [6].

The EMTP-ATP program has been widely used in power quality studies [7],[13],[14] The capability of this tool to the voltage sags analysis is shown in [7].

In this paper an ATP computer model has been developed to obtain the dynamic response of an ASD converter driving an induction motor when voltage is suddenly reduced in the power source. The system under study includes: Faulted power supply, controlled 3-phase full bridge rectifier, VSI inverter, threephase induction motor with a constant torque mechanical load. Voltage and frequency of the motor are controlled using PI regulators.

The transient response of the mechanical and electrical variables caused by symmetrical voltage sags is obtained verifying the capability of each element to manage the fault. The model enables each component of the control circuit to be replaced easily and its impact on the whole installation to be studied.

\section{Voltage-fed inverter drive}

The induction motor drive consists of a three-phase full-bridge converter, Fig.1. A phase-controlled thyristor bridge rectifier with a LC filter supplies dc voltage to the three-phase IGBT bridge inverter.

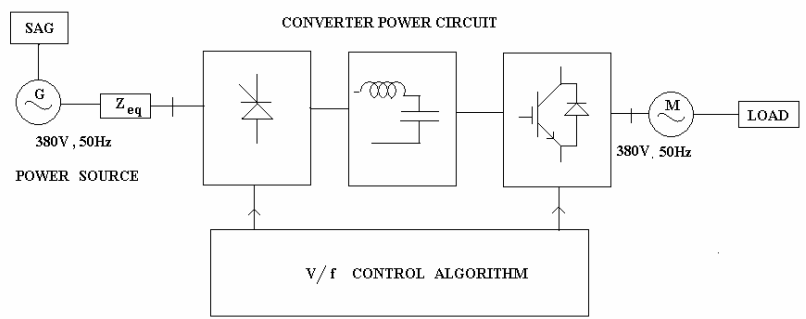

Fig 1.- ASD scheme for induction motor with voltage sag transients 
The switches of the same leg of the inverter are ON for $180^{\circ}$. Each phase of the motor is supplied with a square voltage wave. The switches are fired to regular intervals of $60^{\circ}$, so the phase voltages are mutually phase shifted by $120^{\circ}$. A six-step line voltage is generated at the inverter output.

The electrical frequency applied to the motor and dc voltage in the output of the rectifier are controlled following a linear relationship, Fig 2. The purpose of the volt per hertz control scheme is to maintain the air-gap flux of the induction motor constant in order to achieve higher run-time efficiency. The characteristic is defined by the base point of the motor. Below the base point the motor operates at optimum excitation because of the constant V/f ratio. Above this point, the motor operates under-excited because of the dc-bus voltage limit.

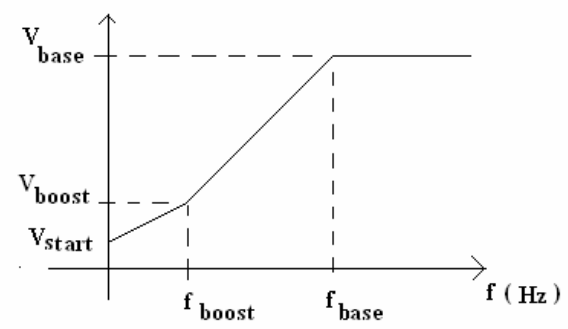

Fig 2.- V/f characteristic

\section{ATP model of the system}

\section{A. Power system model}

The power system is represented by its equivalent Thevenin type 14 ATP sinusoidal source with a peak value of $311 \mathrm{~V}$ of phase, $50 \mathrm{~Hz}$, and the equivalent impedance is given by Req = $0.4 \Omega$ in series with an inductance Leq $=0.52 \mathrm{mH}$. Amplitude modulation MOD was used to simulate the voltage sag. Different shapes of voltage sags can be obtained using the expression [8]

$$
\text { MOD }=\mathbf{P}_{5}(\mathbf{t})+\mathbf{K}_{1} \mathbf{e}^{-\mathbf{K}_{2} \mathbf{t}}
$$

where $\mathrm{P}_{5}(\mathrm{t})$ is a fifth order constant coefficients polynomial. Depth and time parameters are introduced in MODELS.

\section{B. Three-phase full bridge rectifier}

The thyristors are represented with type 11 controlled switches. The pulses to trip the thyristors are generated using the line voltages of the source. The mean dc-bus voltage $\mathrm{Vd}$ is controlled by means of the delay angle $\alpha$. In order to damp the overvoltages in terminals of power switches originated by current interruptions, an R-C snubber circuit is connected in parallel with each thyristor. The L-C filter is connected to the output to obtain a smooth dc output voltage. To eliminate numerical oscillations due to the integration rule a resistance $R_{p}$ is paralled with the inductance[9].

$$
\mathbf{R p}=\frac{20}{3} \frac{2 \mathbf{L}}{\Delta \mathbf{t}}
$$

\section{Inverter model}

The IGBTs in the three-phase inverter bridge are modeled using type 13 controlled switches. Sinusoidal functions with the stator current frequency $\mathrm{f} 1$ are used as order signals to generate trip signals to turn $\mathrm{ON}$ the switches. In turn, $\mathrm{f} 1$ is determined by the control algorithm.

The bypass free-wheeling diodes protect IGBT from reverse bias inductive surges due to motor field decay which happens when the transistors turn off. Moreover, this diode permits reactive power circulation and active power flow in either direction[ Bose]and has been represented using the type 11 switch.

\section{Induction motor}

The type 4 Universal Machine (UM) ATP module was used to represent the $380 \mathrm{~V}, 50 \mathrm{~Hz}$, 4-pole three-phase induction motor. The d-q equivalent circuit consists of 1 coil on both axis. The data of the circuit have been obtained from [10]. The load coupled to the motor consists of a constant torque $\mathrm{Tr}=200 \mathrm{Nm}$. This mechanical load has been modeled by means of its equivalent electrical circuit. The resistant torque has been represented by a type 60 controlled current source. Damping coefficient and inertia momentum are included in the circuit. Uncoupled initialization is used due to non-linearity of components.

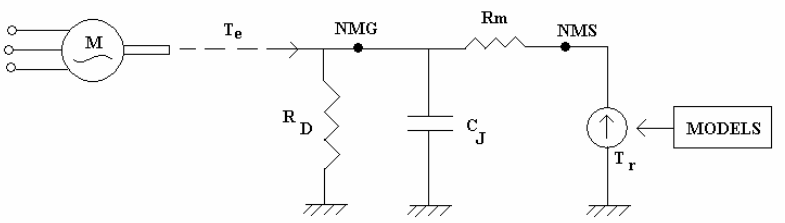

Fig 3.- Mechanical load model

\section{E. Control system}

The closed-loop control system is illustrated in Fig 4. The volts per hertz method controls the magnitude of the frequency and voltage. The command and feedback signals are dc quantities, and are proportional to the respective variables. In steady state operation the machine air-gap flux is approximately related to the ratio $\mathrm{Vs} / \mathrm{fs}$ where $\mathrm{Vs}$ is the amplitude of motor phase voltage and fs is the electrical frequency applied to the motor.

In order to obtain the desired response proportional and integral PI regulators have been used. The proportional controller will have the effect of reducing the rise time and will reduce the steady-state error. The integral control will have the effect of eliminating steady-state error improving the transient response.

The actual motor speed measured for the speed sensor is compared with the reference speed while the error signal is generated. The PI controller processes the speed error and 


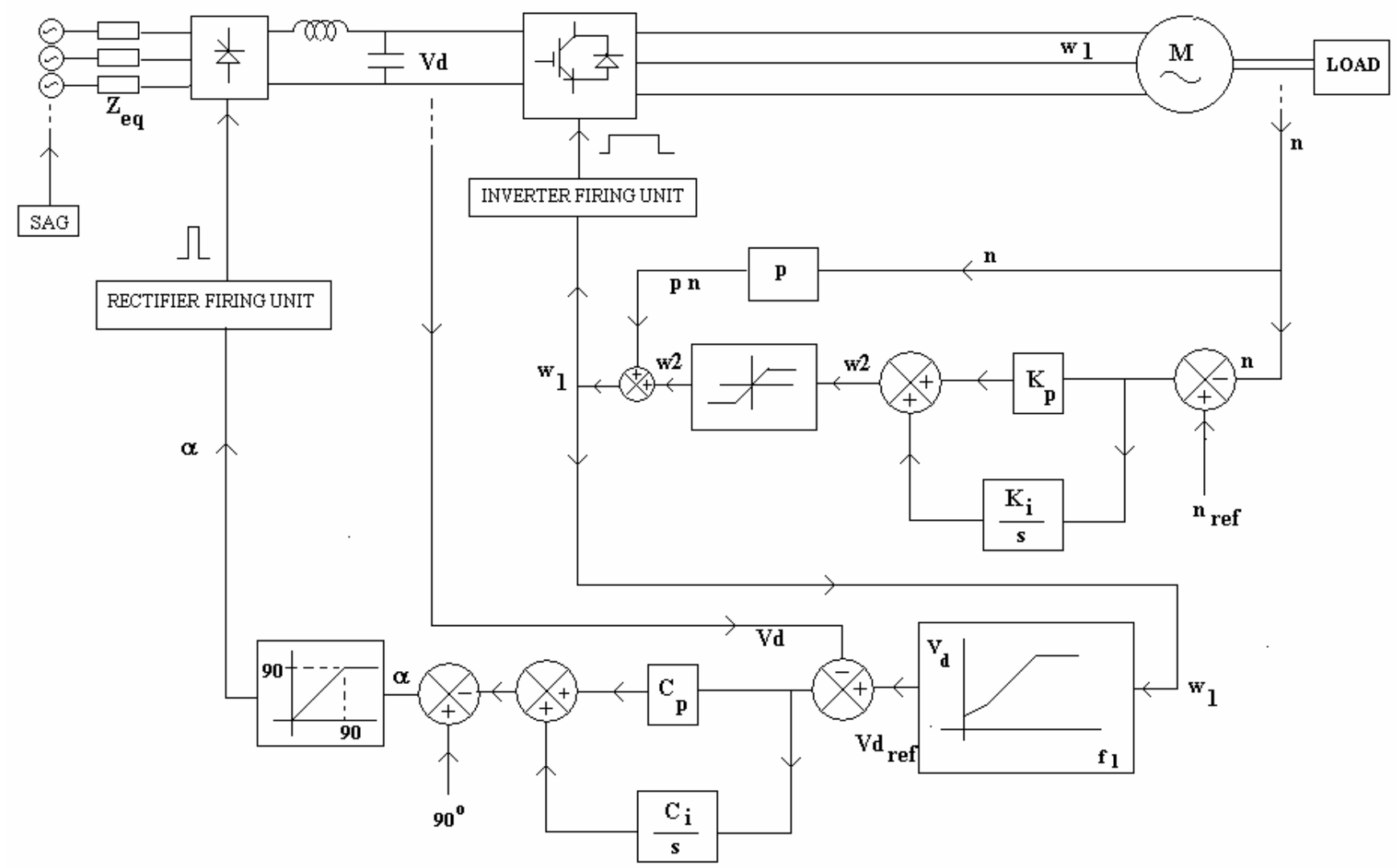

Fig 4. Closed loop control system

generates the corrected frequency of the motor stator. The speed controller constants have been tuned experimentally according to the actual load

$\mathrm{V} / \mathrm{f}$ ratio is constant from 25 to $50 \mathrm{~Hz}$. Vstart $=25 \mathrm{~V}$ is used to improve the starting torque, fboost $=25 \mathrm{~Hz}$, and a fbase $=50 \mathrm{~Hz}$. Above $50 \mathrm{~Hz}$, voltage is fixed to the normal value corresponding to $380 \mathrm{~V}$ and the of the motor is running in a constant power condition. The speed error $\mathrm{w}_{2}=\mathrm{s} \mathrm{w}_{1}$ processed by the PI regulator is limited to the value corresponding to the full load slip. Delay angle $\alpha$ of thyristors is limited to vary from $0^{\circ}$ to $90^{\circ}$.

\section{ATP simulation and results}

The dynamic regime caused by a symmetrical sharp voltage sag has been obtained. A $40 \%$ depth voltage sag, defined in Fig 5 , is applied at 7.0 seconds with a duration of 0.5 seconds. The results are shown in the Figs 5 to 12 corresponding to a reference speed of $140 \mathrm{rad} / \mathrm{sec}$ and a resistant torque of 200 $\mathrm{Nm}$. Mechanical speed undergoes a reduction to $102.2 \mathrm{rad} / \mathrm{sec}$. The overshoot in motor current and power side current appear in the making up period of the voltage.

\section{Conclusion}

An ATP numerical model for a three-phase induction motor with an adjustable speed drive has been developed. The VSI inverter control strategy is based on a closed-loop scheme with a constant ratio volts/freq.
The transient response caused by different types of symmetrical voltage sags in power systems has been obtained. The operation of the control system has been verified. The control system is limited to voltage sags of $40 \%$ magnitude. In order to refine the output for higher depth voltage sags, it is necessary to add the derivative option in the control system (PID control algorithm).

With this model it is possible to replace each component easily, due to its modularity, thus making it possible to analyze the response of different loads connected to the power system.

This numerical tool provides a criteria to prevent undesirable tripping of critical loads.

\section{Acknowledgment}

The authors wish to thank the Spanish Ministry of Science and Technology for the support of the research project "Estudio y desarrollo de nuevas técnicas de procesado aplicadas a la detección, medida y evaluación de la calidad de la energía eléctrica" (DPI2003-08869-C02), of which the present paper is a part.

\section{References}

[1] T. Key "Predicting behaviour of induction motors during service faults and interruptions", IEEE Industry Appl Mag., Jan/Feb 1995

[2] G. Newmann , S. Perera, V. Gosbell, V. Smith "Voltage sag ride through improvment of moderna a.c. drives: Review of 
methods and case study", Proc AUPEC 01, Perth, pp 304309, Perth, Sept 2001.

[3] O. Montero , P. Enjeti, "Application of a boost ac-ac converter to compensate for voltage sags in electric power distribution systems", Proc. IEEE PESC voll. 2000, pp.470-475.

[4] J. L. Duran, P. N. Enjeti, A. von Jouanne, "An approach to achieve ride through of an adjustable speed drive with flyback converter modules powered by super capacitors", IEEE-IAS Annu. Meeting vol3, 1999, pp 1623-1629

[5] W. E., Brumsickle, et al. "Dynamic sag correctors: Costeffective industrial power line conditioning". IEEE Trans. Ind. Appl. Vol 37 , pp 212-217,Jan/Feb 2001.

[6] E. C. Aleoiza, et al. "Analysis and design $\mathrm{f}$ a new voltage sag compensator for critical loads in electrical power distribution systems" IEEE, Trans on Ind. Appl, Vol 39 , No 4 July/August 2003.

[7] J. A. Martinez Velasco, J. Martin-Arnedo "Voltage sag análisis using an Electromagnetic Transient Program" Int Conf on Power Systems Transients CIPST, Louisiana, USA Sep 28-2Oct, 2003

[8] M.A. Rodríguez Pozueta, J. Cardona, L. Mantilla, “Análisis de fallos en la red de $4.16 \mathrm{KV}$ de una central nuclear

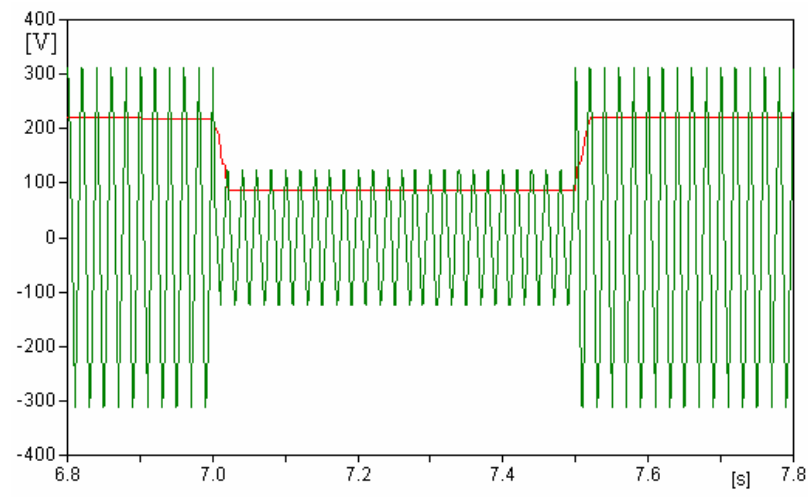

Fig 5. Phase-R voltage of the source and r.m.s. value

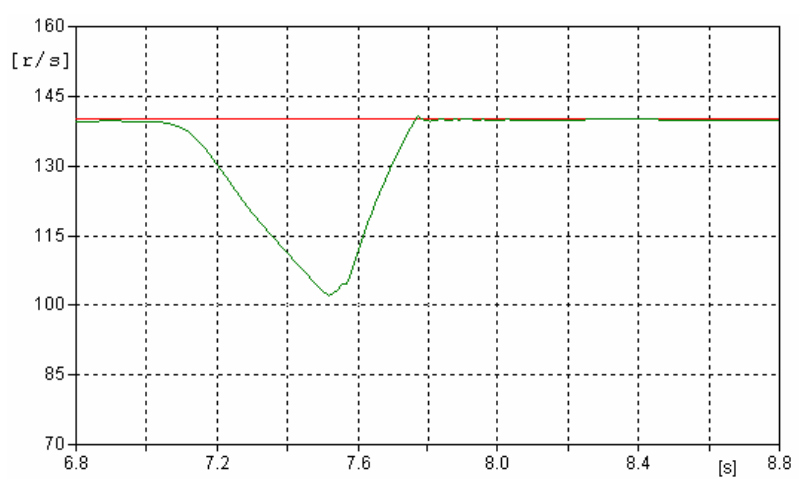

Fig 6. Motor speed and reference speed mediante el programa EMTP-ATP. Actas, V- Jornadas Hispano-Lusas de Ing. Electrica . Univ. Salamanca.,Vol 1, pp 556-562.1997.

[9] Alternative Transient Program "Theory Book", European EMTP-ATP Users Group (EEUG), 2005.

[10] J. A. Martínez Velasco, "Curso de especialización EMTP", U.P.C. Barcelona 1994.

[11] G. A. Alonso Orcajo "Armónicos en forma compleja asociados a las condiciones de funcionamiento de convertidores controlados alterna continua de 6 pulsos". T. Doct., Univ. Oviedo 1998.

[12] B. K. Bose, "Modern Power Electronics, Evolution, Technology and Applications", IEEE Press , New York, 1992

[13] T. Key "Predicting behaviour of induction motors during service faults and interruptions", IEEE Industry Appl Mag., Jan/Feb 1995

[14] G. Newmann , S. Perera, V. Gosbell, V. Smith "Voltage sag ride through improvment of moderna a.c. drives: Review of methods and case study", Proc AUPEC 01, Perth, pp 304-309, Perth, Sept 2001.

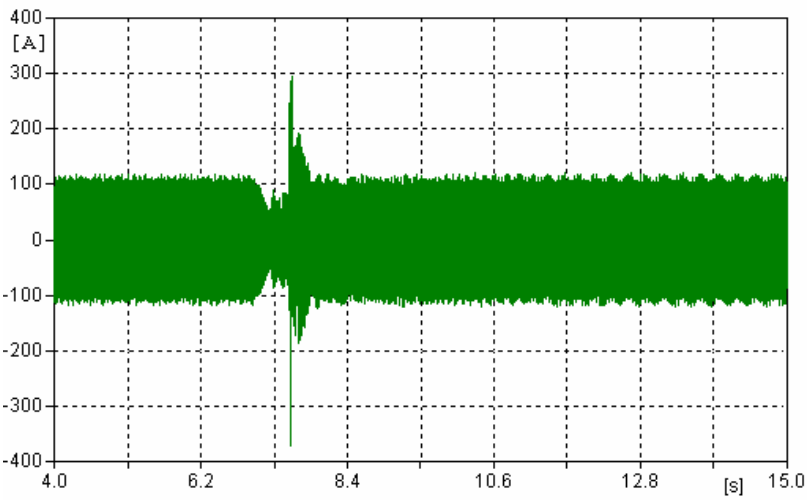

Fig 7. Phase-R current of the motor stator

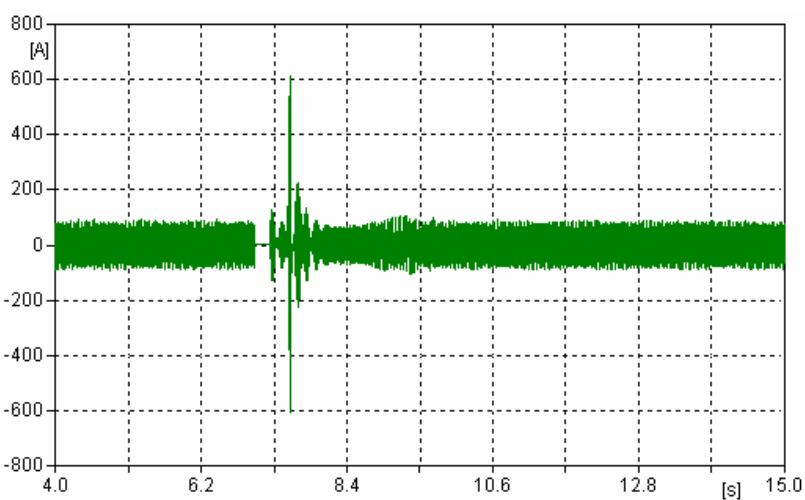

Fig 8. Current on the a.c. power source side of the converter 


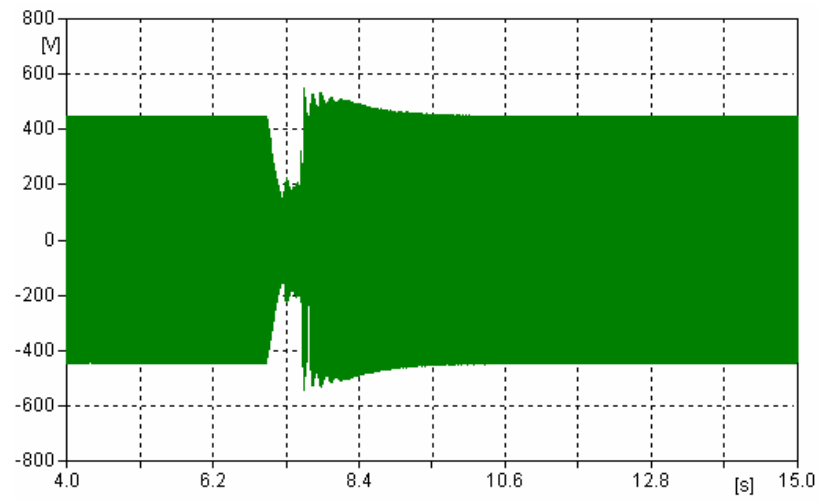

Fig 9. Line voltage in terminals of the motor

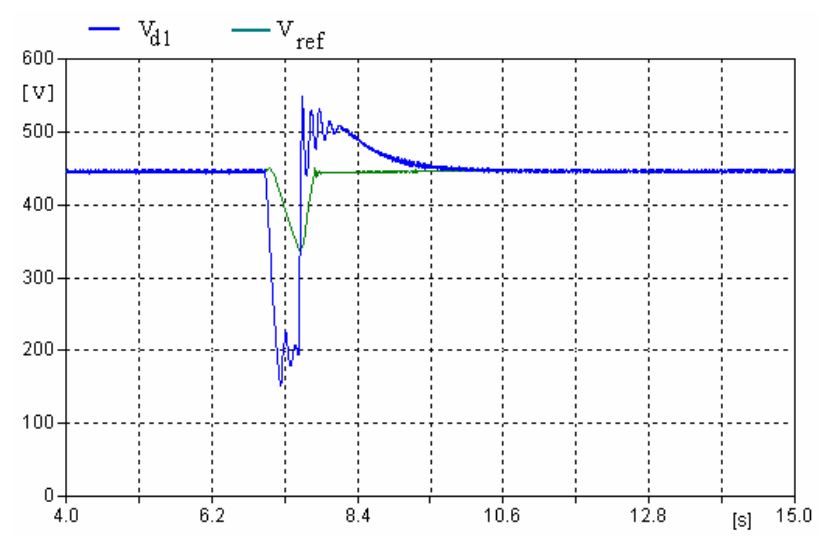

Fig 10. DC voltage supplied by the rectifier in terminals of the inverter $\mathrm{Vd} 1$ and reference Vdref computed by the control system

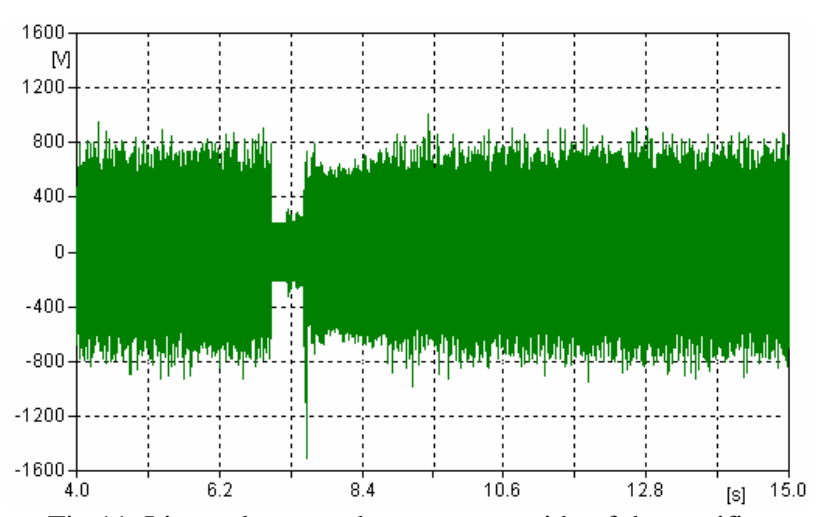

Fig 11. Line voltage on the a.c. power side of the rectifier 